\title{
Novel approaches to risk stratification with semi-quantitative scoring systems in nuclear cardiology
}

\author{
Leslee J. Shaw, $\mathrm{PhD}^{\mathrm{a}}$ \\ ${ }^{a}$ Emory Clinical Cardiovascular Research Institute (ECCRI), Emory University School of Medicine, \\ Atlanta, GA
}

Received May 23, 2014; accepted May 23, 2014

doi: $10.1007 / \mathrm{s} 12350-014-9929-x$

\section{See related article, pp. 807-818}

The body of evidence on the prognostic relationship of segmental scoring of the extent and severity of rest and stress myocardial perfusion imaging abnormalities has been extensively studied across diverse patient populations. ${ }^{1}$ The standardized scoring entails the summing of the severity of reduced perfusion within each of 17 segments to form summed scores at rest and post-stress. This approach has detailed the well-established graded relationship between worsening outcomes and more extensive and severe perfusion abnormalities. ${ }^{1}$ Although generally accepted as the method for documentation of myocardial perfusion imaging findings, the practice of scoring is cumbersome and not without its challenges. Given the time limitations of daily laboratory practices, alternative approaches that simplify scoring have intuitive appeal. In this issue of the journal, Nudi et $\mathrm{al}^{2}$ simplified the segmental model into the most elemental 7 zones that can be mapped to major epicardial coronary arteries. This anatomic approach will be highly valuable to nuclear cardiologists who provide guidance on the need for diagnostic coronary angiography and the likelihood of significant obstructive coronary artery disease necessitating surgical intervention.

Recent evidence reports an exceedingly high rate of normal coronaries at diagnostic coronary angiography; even for patients with prior abnormal stress test

Reprint requests: Leslee J. Shaw, PhD, Emory Clinical Cardiovascular Research Institute (ECCRI), Emory University School of Medicine, 1462 Clifton Road NE, Room 529, Atlanta, GA 30324; lshaw3@emory.edu

J Nucl Cardiol 2014;21:819-20.

$1071-3581 / \$ 34.00$

Copyright (C) 2014 American Society of Nuclear Cardiology. findings. ${ }^{3}$ If a system were in place to more effectively guide the decision for coronary angiography by orchestrating an improved fusing of physiologic with anatomic findings as to the presence and severity of ischemia, this could be invaluable to management decisions for the patient with obstructive coronary artery disease. The inclusion of ischemic findings is a core element of the American College of Cardiology's (ACC) appropriate use criteria for diagnostic catheterization that emphasizes documentation of sufficient ischemia prior to elective percutaneous coronary intervention. ${ }^{4}$ This data is also consistent with the recent stable ischemic heart disease clinical practice guidelines from the ACC whereby ischemia-guided management is the core approach for management of symptomatic patients. ${ }^{5}$ Both documents support the notion that patients with minimal ischemia should not be referred to angiography but the referral should be limited to patients with a sizeable ischemic burden.

Moreover, results from two large randomized trials, entitled the Fractional Flow Reserve vs. Angiography for Multivessel Evaluation (FAME) trials, consistently support that targeting revascularization in ischemic vessels is superior to anatomic-guided percutaneous coronary intervention. ${ }^{6,7}$ These trials provide a great lesson for the field of nuclear cardiology that if we truly link or fuse the anatomic site of stenosis or plaque burden with evidence of scarring or ischemia, then clinical care targeted to the disease state of that patient can be effective and result in improved outcomes. The evidence base is substantial that ischemia-guided care results in substantial and prolonged improvement in clinical symptoms as well as sizeable reductions in ischemia. ${ }^{8,9}$

The current findings integrate the quantitative scores from these 7 regions into a 5-level classification of ischemia. I agree with the authors that this is a parsimonious approach to segmental modeling of the myocardium. This new approach including 7 segments 
was similarly effective at risk stratification when compared to a 20-segment model; however, an internal validation and comparative analysis was not performed. Using this new approach, it will be important to correlate and integrate these perfusion imaging findings into a pathway of care for coronary disease patients presenting for symptom evaluation. Despite this limitation, the current approach has sizeable appeal and may have an ease of assimilation into the busy laboratories in today's hustling nuclear cardiology practice. To that end, this investigative group should be lauded for starting this discussion on advancing the field from the silo approach of image interpretation toward a more integrative interpretation. This should unfurl more research on getting our field inextricably linked into clinical management decisions that are truly guided by ischemia on stress myocardial perfusion imaging.

\section{References}

1. Shaw LJ, Hage FG, Berman DS, Hachamovitch R, Iskandrian A. Prognosis in the era of comparative effectiveness research: Where is nuclear cardiology now and where should it be? J Nucl Cardiol 2012;19:1026-43.

2. Nudi F, Pinto A, Procaccini E, Neri G, Vetere M, Tomai F, et al. A novel clinically relevant segmentation method and corresponding maximal ischemia score to risk-stratify patients undergoing myocardial perfusion scintigraphy. J Nucl Cardiol 2014.

3. Patel MR, Peterson ED, Dai D, Brennan JM, Redberg RF, Anderson $\mathrm{HV}$, et al. Low diagnostic yield of elective coronary angiography. N Engl J Med 2010;362:886-95.

4. Patel MR, Bailey SR, Bonow RO, Chambers CE, Chan PS, Dehmer GJ, et al. ACCF/SCAI/AATS/AHA/ASE/ASNC/HFSA/
HRS/SCCM/SCCT/SCMR/STS 2012 appropriate use criteria for diagnostic catheterization: A report of the American College of Cardiology Foundation Appropriate Use Criteria Task Force, Society for Cardiovascular Angiography and Interventions, American Association for Thoracic Surgery, American Heart Association, American Society of Echocardiography, American Society of Nuclear Cardiology, Heart Failure Society of America, Heart Rhythm Society, Society of Critical Care Medicine, Society of Cardiovascular Computed Tomography, Society for Cardiovascular Magnetic Resonance, and Society of Thoracic Surgeons. J Am Coll Cardiol 2012;59:1995-2027.

5. Fihn SD, Gardin JM, Abrams J, Berra K, Blankenship JC, Dallas AP, et al. 2012 ACCF/AHA/ACP/AATS/PCNA/SCAI/STS guideline for the diagnosis and management of patients with stable ischemic heart disease: A report of the American College of Cardiology Foundation/American Heart Association Task Force on Practice Guidelines, and the American College of Physicians, American Association for Thoracic Surgery, Preventive Cardiovascular Nurses Association, Society for Cardiovascular Angiography and Interventions, and Society of Thoracic Surgeons. J Am Coll Cardiol 2012;60:e44-164.

6. De Bruyne B, Pijls NH, Kalesan B, Barbato E, Tonino PA, Piroth Z, et al. Fractional flow reserve-guided pci versus medical therapy in stable coronary disease. N Engl J Med 2012;367:991-1001.

7. Tonino PA, De Bruyne B, Pijls NH, Siebert U, Ikeno F, van't Veer $\mathrm{M}$, et al. Fractional flow reserve versus angiography for guiding percutaneous coronary intervention. N Engl J Med 2009;360:21324.

8. Boden WE, O'Rourke RA, Teo KK, Hartigan PM, Maron DJ, Kostuk WJ, et al. Optimal medical therapy with or without pci for stable coronary disease. N Engl J Med 2007;356:1503-16.

9. Shaw LJ, Berman DS, Maron DJ, Mancini GB, Hayes SW, Hartigan PM, et al. Optimal medical therapy with or without percutaneous coronary intervention to reduce ischemic burden: Results from the Clinical Outcomes Utilizing Revascularization and Aggressive Drug Evaluation (COURAGE) trial nuclear substudy. Circulation 2008;117:1283-91. 